\title{
RESPONSABILIDADE PENAL DA PESSOA JURÍDICA POR CRIMES \\ AMBIENTAIS À LUZ DO MODELO CONSTRUTIVISTA DE \\ AUTORRESPONSABILIDADE
}

\section{CRIMINAL RESPONSIBILITY OF LEGAL ENTITIES FOR \\ ENVIRONMENTAL CRIMES FROM THE UNDERSTANDING OF THE CONSTRUCTIVIST MODEL FOR AUTORESPONSIBILITY}

\author{
Fabio Andre Guaragni ${ }^{1}$ \\ Ellen Galliano de Barros ${ }^{2}$ \\ Manoela Pereira Moser $^{3}$
}

\section{Resumo}

Esta pesquisa tem por objetivo analisar qual o modelo de responsabilidade penal da pessoa jurídica é mais compatível com o ordenamento jurídico brasileiro e com os princípios do Direito Penal moderno, através do método bibliográfico e jurisprudencial. Para tanto, far-se-á, primeiramente, uma breve análise da sociedade contemporânea do risco atrelada à proteção do meio ambiente e os impactos sociais na dogmática penal. Após, será examinada a responsabilidade penal da pessoa jurídica, através da previsão constitucional e legal, bem como do modelo teórico adotado. Por fim, analisar-se-á a vertente teórica construtivista de autorresponsabilidade da pessoa jurídica contemplada nas lições de Carlos Gómez-Jara Díez, como sustentáculo da teoria do delito para entes morais.

Palavras-chave: Responsabilidade Penal da Pessoa Jurídica, Crimes Ambientais, Autorresponsabilidade, Modelo Construtivista, Compliance.

\section{Abstract/Resumen/Résumé}

\footnotetext{
${ }^{1}$ Doutor em Direito das Relaçoes Sociais (UFPR), com estudo Pós-doutoral na Universita degli Studi di Milano. Professor de Direito Penal do Mestrado do Unicuritiba e FEMPAR.

${ }^{2}$ Mestranda em Direito Empresarial e Cidadania pelo Centro Universitário Curitiba. Pós-Graduada em Direito Penal e Direito Processual Penal pelo Centro Universitário Curitiba (2019). Bacharel em Direito pela Pontifícia Universidade Católica do Paraná (2017). Assessora Jurídica da $4^{a}$ Câmara Criminal do Tribunal de Justiça do Estado do Paraná.

3 Mestranda em Direito Empresarial e Cidadania pelo Centro Universitário Curitiba - UNICURITIBA. Especialista em Direito Penal Econômico pela Universidade Positivo. Especialista em Ministério Público Estado Democrático de Direito, área de concentração em Direito Processual Penal pela na FEMPAR (Fundação Escola do Ministério Público). Bacharel em Direito Centro Universitário Curitiba - UNICURITIBA (2012). Advogada.
} 
This research aims to analyze which model of criminal liability of the legal entity is more compatible with the Brazilian legal system and with the principles of modern Criminal Law, through the bibliographic and jurisprudential method. To this end, we will first make a brief analysis of contemporary society of risk linked to environmental protection and social impacts on criminal dogmatica. Afterwards, the criminal liability of the legal entity will be examined, through constitutional and legal provision, as well as the theoretical model adopted. Finally, the constructivist theoretical aspect of self-responsibility of the legal entity contemplated in the lessons of Carlos Gómez-Jara Díez will be analyzed as a support of the theory of crime for moral entities.

Keywords/Palabras-claves/Mots-clés:Criminal Responsibility of Legal Entities, Environmental Crimes, Autoresponsibility, Constructivist Model, Compliance.

\section{INTRODUÇÃO}

Conforme Jesús-Maria Silva Sánchez (2001), o Direito Penal sofreu uma expansão a partir da criação de novos riscos, novos sujeitos e novos bens jurídicos.

As principais causas deste fenômeno se relacionam à nova realidade, composta por radicais mudanças sociais e culturais, cumulado ao fato de que bens que antes eram abundantes tornaram-se escassos (SÁNCHEZ, 2001, p. 25).

Logo, bens coletivos e interesses difusos, tal como o meio ambiente sustentável, não apenas foram consagrados como direitos fundamentais, como também passaram a ser protegidos pelo Direito Penal; e, por conseguinte, pessoas jurídicas são passíveis de responsabilização criminal, haja vista o seu protagonismo em ilícitos em desfavor do ecossistema e de todas as formas de vida.

Neste cenário, a teoria do delito tradicional, construída para a pessoa física, é insuficiente para a necessidade contemporânea, melhor dizer, os conceitos de dolo, autoria, culpabilidade e características da pena, devem ser adaptados para abranger os novos sujeitos, como as complexas organizações empresariais.

Os delitos praticados no âmbito da corporação possuem características próprias que dificultam, e muitas vezes, impossibilitam a imputação da responsabilidade penal. Observa-se, no momento da individualização da conduta, que a pluralidade de agentes e a estrutura organizacional, relacionada à fragmentação de informação, à divisão de tarefas e à delegação 
de funções, permitem que diversos sujeitos participem, de maneira quantitativa e qualitativa, para a prática da conduta criminosa, conduzindo a uma irresponsabilidade organizada (ESTELLITA, 2017).

De mais a mais, em sua maioria, os bens jurídicos afetados pelas ações ou omissões dessas organizações possuem natureza coletiva, e são afastados do autor por questão de tempo ou espaço, influenciando na identificação da causalidade entre a ação/omissão e o resultado lesivo (ESTELLITA, 2017, p. 41-42).

Por estas razões, faz-se necessária realizar a análise dogmática acerca do modelo de responsabilidade penal da pessoa jurídica, optando-se pela vertente construtivista da autorresponsabilidade de Carlos Gómez-Jara Díez, capaz de adaptar o Direito Penal - dogmática e política-criminal - à realidade contemporânea.

\section{EVOLUÇÃO SOCIOECONÔMICA E AMBIENTAL: DA ERA DO MEDIEVO À SOCIEDADE DE RISCO}

Para melhor compreender a temática da responsabilidade criminal da pessoa jurídica em matéria ambiental, cumpre examinar os fatores que impactaram a criação de novos bens jurídicos e o Direito Penal, especificamente a transformação socioeconômica e ambiental, a qual se traduz na atual Sociedade de Risco.

Assim, destaca-se que, para a chegada da sociedade constituída a partir do risco, foi necessária a partida da Era do Medievo (HOBSBAWM, 2010, p. 37-50), na qual havia a convivência integrada e pacífica entre o homem e a natureza, em razão da produção agrária e artesanal, não havendo, portanto, a supremacia de um sobre o outro. Mais que isto, os desastres ambientais eram advindos da própria natureza, sem a interferência humana (BECK, 2006, p. $78)$.

Após a ocorrência da "Dupla Revolução" (HOBSBAWM, 2010, p. 20-50), por efeito da Revolução Francesa (ideais iluministas para o cenário ideológico e político) e da Revolução Industrial (transformação socioeconômica), surge a segunda sociedade, denominada industrial. Foi marcada pela estruturação sólida e previsível, com a prevalência da racionalidade antropocêntrica e científica, divisão de classes e, sobretudo, pela industrialização em larga escala.

O comércio massificado foi possível não apenas pelo avanço tecnológico e científico, com a criação e o emprego de grandes maquinários, como também pela exploração da força 
humana, a partir do trabalho exaustivo, em ambientes insalubres e da mão de obra barata. Acrescenta-se, na mesma linha, o uso excessivo dos recursos naturais, outro fator necessário ao alcance da lucratividade dos entes privados, sempre justificado pela melhoria da qualidade de vida e pelo combate à miséria.

Com a lógica da fonte inesgotável dos recursos ambientais, o culto à ciência e à superioridade do homem, sobreveio a dissociação entre o indivíduo e o meio ambiente, e mais, novas ameaças à natureza, por meio do acréscimo decorrente da decisão humana, individual ou coletiva, governamental ou não (BECK, 2009, p. 25), vale dizer, foram criados riscos fabricados.

Para além, mediante a adoção do sistema capitalista e de produção intensa, foi revelada a conversão de riscos em danos ambientais. A propósito, menciona-se a definição de risco, consoante os ensinamentos de Ulrich Beck:

\footnotetext{
O risco não é sinônimo de catástrofe. Risco significa a antecipação da catástrofe. Os riscos dizem respeito à possibilidade de futuros desenvolvimentos e ocorrências; fazem presente um estado de mundo que (ainda) não existe. Enquanto toda catástrofe é espacial, temporal e socialmente determinada, falta à antecipação da catástrofe qualquer concretude espaço-temporal ou social. Assim, a categoria de risco significa a controversa realidade do possível, o qual deve ser demarcado de meramente possibilidade especulativa, de um lado, e de efetiva ocorrência de catástrofe, de outro. $\mathrm{O}$ momento em que os riscos se tornam reais, quando uma usina nuclear explode ou um ataque terrorista ocorre, eles viram catástrofes. Riscos são sempre eventos futuros que podem ocorrer e que nos ameaçam. Mas porque este constante perigo dá forma às nossas expectativas, se alojam em nossas cabeças e guiam as nossas ações, eles se tornam uma força política que transforma o mundo. (BECK, 2009, p. 09-10)
}

O risco, então, até a sociedade industrial, era concreto, previsível, calculável e quantificado, com a possibilidade de ter a sua extensão e seus efeitos visualizados, e, por conseguinte, com o aparelhamento suficiente para obstá-lo. Em síntese, eram considerados meros efeitos colaterais obscuros, pois necessários ao crescimento econômico.

Por essa visão de mundo essencialmente egoísta, os riscos gradualmente foram potencializados, tolerados pela sociedade, ocultados e negados por agentes estatais e econômicos, viabilizando, assim, o surgimento de ameaças de prejuízos imprevisíveis, abstratos e incalculáveis.

O progresso obtido na etapa social intermediária marcou a autodestruição das formas de vida e a sua incerteza, características próprias da atual sociedade, denominada por Beck de "Sociedade de Risco" ou "Modernidade Reflexiva".

Nessa terceira etapa, a crise ambiental (existencial) se tornou explícita, considerando a intensificação do processo de modernização anterior, o que resultou no aumento da exploração 
do meio ambiente (atividades ilícitas e uso massivo dos recursos naturais), por meio da industrialização de escala global, da inovação da informatização e do processo de globalização. Ambos voltados à superprodução e à aceleração do consumo (IANNI, 2011, p. 211).

Como mencionado, os riscos deixaram de ter concretude e previsibilidade, melhor dizer, fogem dos padrões de cálculo, extrapolam o controle feito pela ciência e de organismos públicos e privados, inclusive são capazes de multiplicar outras espécies danos à humanidade, para além dos materiais e morais. Há uma insuficiência/falência das "relações de definição", caracterizadas como formas de constatação, definição e contenção de prováveis prejuízos ecológicos, como explana David Goldblatt (1996, p. 241).

Além do mais, as novas possibilidades de prejuízos transcendem fronteiras e são supranacionais (BECK, 2011, p. 42), afastando-se do controle e da avaliação feita pelos Estados, além atingirem toda a coletividade, independendo de qualquer distinção e geração, pois mantêm seus efeitos até as próximas gerações (AYALA, 2004, p. 229-268).

Por constituir força que prejudica toda a humanidade, Beck (2011, p. 44-45) afirma que até mesmo quem produziu o risco, na posição de culpado, será vítima, descrevendo seu "efeito boomerang". Aliás, a reflexividade desta sociedade é evidenciada, porque, em primeiro lugar, na medida em que se tem a evolução socioeconômica, por meio do comportamento negligente, irracional e despreocupado com a população e a ecologia, as consequências negativas retornam contra o próprio homem.

Em segundo, a crise existencial é tão severa e nítida, que gera a perturbação social, haja vista a incerteza dos novos e desconhecidos riscos, e mais, fomenta a tomada da consciência coletiva de todos os seus impactos e a necessária reversão deste cenário, baseado na fixação de limites ao desenvolvimento econômico.

No entanto, em que pese a compreensão do descompasso entre sistema social e o meio ambiente, tem-se a manutenção do status a quo, pelo encobrimento da origem e das consequências advindas de prováveis riscos, além da criação de uma perspectiva de normalidade, por agentes públicos e econômicos, traduzindo, assim, a "irresponsabilidade organizada" (LEITE; BELCHIOR, 2012, p. 01). Outrossim, o "estado segurança" que anteriormente se comprometia a proteger a população, está fragilizado por conta da insuficiência das suas estruturas de fiscalização, prevenção e repressão de ações antiecológicas (GOLDBLATT, 1996, p. 258).

$\mathrm{Na}$ mesma linha, a ciência tem a sua credibilidade afetada, isto porque, tornou-se coprodutora dos riscos, bem como não apresenta respostas para impedi-los. Logo, demonstra a 
sua falibilidade e a colaboração com a realidade insustentável (BAHIA, 2014, p. 58).

Outro fator que reforça este cenário é a presença de brechas nos sistemas legislativo e jurídico, obstando a devida responsabilização dos agentes criminosos. Isto advém de negociações entre membros públicos e privados, visando os seus interesses particulares, ainda, a aparente proteção abarcada pela legislação, a manipulação de informações de prejuízos e a falta de instrução de casos judiciais e de evidencias robustas para a comprovação de ilicitudes. Trata-se, portanto, da função simbólica do direito e do sistema jurídico-legislativo, retórico e deficiente, conforme salienta Heline Sivini Ferreira (2008, p. 63).

Como resultado de todas as circunstâncias, surge a "explosividade social do risco", configurada pela revolta por parte da população quando noticiado dano grave e de grande proporção, já que, até então, havia um “controle” informado pelos órgãos públicos, pela mídia e pela elite econômica.

Mesmo diante dos protestos e das cobranças coletivas, permanece a tolerância dos riscos, um comportamento apático, acomodado e despreocupado, enquanto não sobrevém tragédia alguma, isto é, "limites de tolerância", que comporta o aceite de prováveis danos e seus impactos (RUTTE; KOZICKI; RIOS, 2013, p. 26).

Os sinais de desequilíbrio e de esgotamento do planeta - crise civilizacional - (LEFF, 2010, p. 61), intensificados pelo avanço socioeconômico alinhado ao aspecto ambiental, anunciam o urgente resguardo ao meio ambiente ecologicamente equilibrado e da dignidade humana, não apenas pela postura proativa e consciente do homem, como ser fraterno, mas também pelo papel das empresas e do próprio Estado. Logo, todos estes, como atores sociais, devem multiplicar comportamentos e ações fiscalizatórias e preventivas em prol da sustentabilidade ecológica, através da comunicação do risco (HOFMEISTER, 2002, p. 41).

O cenário acima descrito influenciou, de sobremaneira, na consagração na proteção do ecossistema equilibrado, tanto na sua consagração como direito fundamental, como bem jurídico resguardado pelo Direito Penal, os quais serão explanados a seguir.

\section{PROTEÇÃO DO MEIO AMBIENTE NATURAL E SEUS IMPACTOS NO DIREITO PENAL}

Após a consciência dos efeitos nocivos ao equilíbrio ambiental e das demais violações transindividuais - contra uma coletividade indeterminada -, advindos do progresso econômico e do comportamento humano irracional, aparece, a partir da segunda metade do século XX, a 
previsão dos direitos fundamentais de terceira geração, de vertente solidária, dentre eles o meio ambiente natural (CIRNE, 2018, p. 225).

Nessa linha, a Constituição Federal de 1988 trouxe a proteção ao meio ambiente ecologicamente equilibrado no artigo 225, caput, que versa sobre vários significados, segundo analisa Mariana Barbosa Cirne (2018, p. 235), respectivamente: o equilíbrio como busca de harmonia entre os elementos da natureza e o homem; decorre do direito à vida, como qualidade de vida; bem incorpóreo, de interesse público, pertencente à coletividade; dever de responsabilidade compartilhada; direito com uma perspectiva para o futuro; participação popular; imposição ao Estado de limitar as atividades que causem degradação; sustentabilidade, pois as gerações atuais não podem deixar para as gerações futuras um estoque inferior de recursos ambientais; e o desenvolvimento sustentável, em facetas social, econômica e ambiental.

No $§ 3^{\circ}$ o mesmo artigo, introduziu pela primeira vez em nosso ordenamento jurídico a possibilidade da responsabilidade penal da pessoa jurídica no âmbito criminal por ato ilícito contra a sustentabilidade ambiental. Trata-se, na verdade, de uma "cláusula criminalizadora constitucional" (GUARAGNI, 2014, p. 34), na qual obriga a legislação extravagante criminalizar condutas antiecológicas. Veja-se:

\footnotetext{
Art. 225. Todos têm direito ao meio ambiente ecologicamente equilibrado, bem de uso comum do povo e essencial à sadia qualidade de vida, impondo-se ao poder público e à coletividade o dever de defendê-lo e preservá-lo para as presentes e futuras gerações.

(...)

$\S 3^{\circ}$ As condutas e atividades consideradas lesivas ao meio ambiente sujeitarão os infratores, pessoas físicas ou jurídicas, a sanções penais e administrativas, independentemente da obrigação de reparar os danos causados. (BRASIL, 1988)
}

Em obediência ao mandamento constitucional, a Lei $n^{\circ}$ 9.605/98 (Lei de Crimes Ambientais) criminalizou uma série de ações em desfavor da sustentabilidade ecossistêmica, bem como instituiu sanções penais e circunstâncias próprias da dosimetria da pena, tanto para a pessoa física, quanto para a pessoa jurídica.

Assim, no seu artigo $3^{\circ}$, fixou a tríplice responsabilidade para pessoa jurídica (administrativa, civil e penal), desde que a infração seja cometida por decisão de representante legal ou contratual, ou do órgão colegiado, com vistas ao interesse ou benefício da entidade. Para mais, indicou que tal responsabilidade não exclui a da pessoa física (autora, co-autora ou partícipe) (BRASIL, 1998). 
Porém, alguns doutrinadores manifestam suas críticas. De acordo com Luiz Luisi (2001, p. 88-89) e Luiz Regis Prado (2001, p. 108), o texto viola princípios explícitos como pessoalidade da pena e da culpabilidade, pois as penas aplicadas a pessoa jurídica sempre atingirá o patrimônio das pessoas físicas que a integram.

No mesmo sentido, segundo René Ariel Dotti (2001, p. 150), da leitura do supracitado artigo deve-se concluir que "tanto a pessoa física quanto a pessoa jurídica podem responder nas ordens civil, administrativa e tributária pelos seus atos; mas que a responsabilidade penal continua sendo de natureza e caráter estritamente humanos."

A Legislação, ainda, traz um rol de penas destinadas a pessoa jurídica criminosa no artigo 21 a 23, respectivamente: multa; restritiva de direitos; e prestação de serviço à comunidade. Existe, ainda, a possibilidade de o ente moral ter decretada a liquidação forçada, no caso de ser constituído ou utilizado para fins criminosos, como descreve o artigo 24.

Pois bem. Foi nessa perspectiva da complexidade social, acompanhada da previsão constitucional e infraconstitucional, que a dogmática penal clássica foi impactada, isto em razão da criação de bens jurídicos que extrapolam a esfera individual - de caráter transindividual e intergeracional -, e na reprimenda de pessoas não físicas.

A razão para essas alterações no sistema penal recai sobre a sua relação com a Modernidade Reflexiva, tornando possível e eficiente o sistema de segurança ambiental (FIGUEIREDO, 2008, p. 233-234), com a finalidade de evitar o surgimento de novos riscos de danos a toda coletividade indeterminada.

Em outras palavras, utiliza-se de novas categorias dogmáticas, as quais modificam a estrutura daquelas construídas para o homem, em relação aos princípios gerais, à teoria do delito e à teoria da pena. A título exemplificativo, tais transformações constituem os seguintes obstáculos a serem superados: enunciados simples dos tipos penas; a falta de rigor técnicocientífico; a dependência para com a seara administrativa; a utilização de conceitos indeterminados; o excesso de normas penais em branco e de perigo abstrato; o exagero da tutela criminal; a violação de princípios penais de ordem constitucional e postulados políticocriminais; e, sobretudo, a responsabilidade da pessoa jurídica. (GOMES; BIANCHINI, 2002, p. 60)

Especificamente quanto à responsabilidade criminal, sabe-se que o Código Penal de 1940 apresenta a sua constituição subjetiva, individual e pessoal, de modo que não existe delito sem dolo (vontade e consciência de agir) ou culpa (imprudência, negligência ou imperícia) e a pena não ultrapassar a pessoa do acusado. 
Logo, prevalecia o princípio da irresponsabilidade penal da pessoa jurídica, qual seja, societas delinquere non potest, fundamentado na ausência de características indispensáveis para atribuir responsabilidade penal à pessoa jurídica, respectivamente: “a) capacidade de ação no sentido penal estrito; b) capacidade de culpabilidade (princípio da culpabilidade); c) capacidade de pena (princípio da personalidade da pena)"(PRADO, 2001, p. 104).

Dessa forma, observa-se que as previsões acima transcritas e as consequentes alterações rompem, por completo, a ideia do princípio societas delinquere non potest, o que gera uma série de debates doutrinários e jurisprudenciais, favoráveis e desfavoráveis à referida responsabilização.

De um lado, tem-se a corrente que admite a responsabilização da pessoa jurídica, pois com esta será possível garantir uma maior reprovação à prática antiecológica, e mais, não haveria impactos negativos aos princípios gerais do Direito Penal, além de indicar a ineficiência das outras modalidades de reprimenda (civil e administrativa). Por derradeiro, fundamenta a sanção na previsão constitucional, que seria a vontade superior no sistema jurídico (PISA, 2009, p. 45).

Em contrapartida, a corrente que discorda da responsabilidade penal sustenta a violação aos princípios fundamentais do ramo criminal, tais como o nullum crimen sine actione, da culpabilidade, da pessoalidade e dos fins da pena, haja vista a intervenção mínima do Direito Penal (PISA, 2009, p. 44).

Em que pese a discussão doutrinária, o STF já se pronunciou na decisão do Recurso Extraordinário 548181, de agosto de 2013, sobre a admissibilidade da condenação de pessoa jurídica por prática de crime ambiental, mesmo que absolvida a pessoa física. A propósito:

RECURSO EXTRAORDINÁRIO. DIREITO PENAL. CRIME AMBIENTAL. RESPONSABILIDADE PENAL DA PESSOA JURÍDICA. CONDICIONAMENTO DA AÇÃO PENAL À IDENTIFICAÇÃO E À PERSECUÇÃO CONCOMITANTE DA PESSOA FÍSICA QUE NÃO ENCONTRA AMPARO NA CONSTITUIÇÃO DA REPÚBLICA. $1 . \mathrm{O}$ art. $225, \S 3^{\circ}$, da Constituição Federal não condiciona a responsabilização penal da pessoa jurídica por crimes ambientais à simultânea persecução penal da pessoa física em tese responsável no âmbito da empresa. A norma constitucional não impõe a necessária dupla imputação. 2. As organizações corporativas complexas da atualidade se caracterizam pela descentralização e distribuição de atribuições e responsabilidades, sendo inerentes, a esta realidade, as dificuldades para imputar o fato ilícito a uma pessoa concreta. 3. Condicionar a aplicação do art. $225, \S 3^{\circ}$, da Carta Política a uma concreta imputação também a pessoa física implica indevida restrição da norma constitucional, expressa a intenção do constituinte originário não apenas de ampliar o alcance das sanções penais, mas também de evitar a impunidade pelos crimes ambientais frente às imensas dificuldades de individualização dos responsáveis internamente às corporações, além de reforçar a tutela do bem jurídico ambiental. 4 . A identificação dos setores e agentes internos da empresa determinantes da produção do fato ilícito tem relevância e deve ser buscada no caso concreto como forma de esclarecer se esses indivíduos ou órgãos 
atuaram ou deliberaram no exercício regular de suas atribuições internas à sociedade, e ainda para verificar se a atuação se deu no interesse ou em benefício da entidade coletiva. Tal esclarecimento, relevante para fins de imputar determinado delito à pessoa jurídica, não se confunde, todavia, com subordinar a responsabilização da pessoa jurídica à responsabilização conjunta e cumulativa das pessoas físicas envolvidas. Em não raras oportunidades, as responsabilidades internas pelo fato estarão diluídas ou parcializadas de tal modo que não permitirão a imputação de responsabilidade penal individual. 5. Recurso Extraordinário parcialmente conhecido e, na parte conhecida, provido. (BRASIL, 2013)

O que se percebe, de tudo isso, é o necessário aprimoramento do sistema criminal, dialogando com outros saberes e sem ignorar a realidade social, da qual reclama maior resguardo ao bem jurídico ambiental, com medidas preventivas, corretivas e de reprovabilidade viável do agente infrator, seja físico ou jurídico.

A modificação apontada diz respeito à todas as categorias dogmáticas, compreendendo a construção adequada e precisa dos tipos penais, o fortalecimento de instrumentos de políticacriminal, com a parceria entre os órgãos estatais e os entes empresariais, a adaptação das teorias do delito e da pena para a devida reprovação da pessoa jurídica.

Apesar da divergência de entendimentos relacionados à responsabilidade em comento, cumpre ao Direito- ao lado das searas administrativa e cível - não negligenciar a proteção de interesses supraindividuais, os quais são, em grande parte, alvo dos riscos produzidos pela atividade econômica de grandes corporações. Tem-se, assim, a urgente atualização do sustentáculo da responsabilidade criminal da pessoa jurídica, uma, em razão da distribuição dos riscos (base sociológica), e dois, pela percepção da alteridade, vale dizer, na ideia solidária de que "[...] Cada indivíduo depende do outro para ser percebido como existência [...]" (GUARAGNI, 2014, p. 37).

À vista desse panorama, seguidamente, serão examinados os dois fundamentos da responsabilização do ente moral, destacando aquele que melhor enquadra a atuação do Direito Penal com a realidade social, sem descuidar dos seus princípios e regras básicas, além de tornar eficaz a preservação do ambiente natural.

\section{MODELO CONSTRUTIVISTA DE AUTORRESPONSABILIDADE PENAL DA PESSOA JURÍDICA}

Como visto, não obstante a existência da previsão constitucional e legal da responsabilidade da pessoa jurídica, esta resta condicionada à sanção da pessoa física, resultando na impunidade de atos lesivos em desfavor do ecossistema e de todas as suas formas 
de vida. Mais ainda, é de se destacar que essa dependência motivada pela não atualização da dogmática penal, torna contínua a cultura empresarial antiecológica, afinal, basta punir e substituir apenas agentes físicos, sem observar o comportamento desviado de toda a corporação.

Assim, da leitura do artigo $3^{\circ}$, da Lei de Crimes Ambientais, observa-se que o legislador adotou o modelo de heterorresponsabilidade, no qual é imprescindível que uma pessoa física tenha agido em interesse ou em benefício do ente coletivo para a possível imputação deste. Tem-se, desta forma, a implantação do sistema de dupla imputação - responsabilização paralela da pessoa física e da jurídica (SCHECAIRA, 2003, p. 194) -,contemplando o concurso obrigatório de agentes, pois apresenta a lógica de o ente moral só será denunciado, desde que uma pessoa física seja corresponsável (GOMES; MACIEL, 2011, p. 12).

No entanto, este modelo, apesar se adequar à teoria clássica do delito, apresenta três grandes problemas para a imputação da responsabilidade, quais sejam: a) dificuldade de identificação do autor; b) impunidade quando a pessoa física possui algum tipo de exculpante ou causa de justificação; e c) quando o delito é praticado por alguém de baixa hierarquia, não podendo afirmar que a ação do autor representaria a vontade da empresa (DETZEL, 2016, p.54).

Por estes déficits, surge a autorresponsabilidade, na qual a corporação é responsabilizada por fato próprio, sendo desnecessária a dupla imputação. Embora não seja compatível com a dogmática tradicional, diante da comprovação das categorias da ação, da culpabilidade e da capacidade penal da pessoa jurídica (TIEDEMANN, 1995, p. 625), possui alguns benefícios no combate à irresponsabilidade organizada.

As vantagens recaem desde a superação da identificação da autoria da pessoa física, passando pela adoção de programas de integridade e de mecanismos de defesa no âmbito do ente coletivo (GÓMEZ-JARA DIEZ, 2015, p. 4;58-60).

Para enfrentar os óbices relativos à base da presente responsabilização, acredita-se que o modelo de autorresponsabilidade nos parece mais correto sob o ponto de vista dogmático e político-criminal, de viés construtivista de Carlos Gómez-Jara Díez.

O referido autor, no seu livro "A responsabilidade penal da pessoa jurídica: Teoria do crime para pessoas jurídicas", pretende apresentar as bases teóricas para a aplicação das previsões da lei sobre crimes ambientais em conformidade com o Direito Penal e com a realidade social das pessoas jurídicas (GÓMEZ-JARA DIEZ, 2015, p. 1), a partir da utilização do modelo construtivista. Com isto, seria proporcionada a autorregulação e um sistema justo e eficaz de responsabilização (GÓMEZ-JARA DIEZ, 2015, p. 12). 
Tal objetivo se justifica pela deficiência estatal quanto ao conhecimento técnico sobre riscos ambientais, pela instituição necessária da autorregulação (cooperação recíproca entre Estado e empresas), além da ausência de fundamentos da responsabilidade pelos tribunais, da proteção adequada do ecossistema e, sobretudo, da compreensão das categorias autônomas da imputação penal de entes coletivos (GÓMEZ-JARA DIEZ, 2015, p. 01-12).Como se percebe, todas estas circunstâncias estão vinculadas às transformações sociais ocorridas ao longo do tempo, que deram entrada à Sociedade de Risco.

Desta feita, Gómez-Jara utiliza-se do modelo "construtivista operativo", base epistemológica da Teoria dos Sistemas sociais autopoiéticos de Niklas Luhmann. A explicação que se faz é da criação de um sistema que se sustenta por si próprio, constitui seus elementos e seu operacional (LINHARES; OLIVEIRA, 2015, p. 41). A esta constituição e sistemática se dá o nome de autorreferenciabilidade, isto é, a capacidade do sistema se produzir por seus elementos/produtos, mediante a autopoiese - produção própria -. (GÓMEZ-JARA DIEZ, 2015, p. 19)

Logo, a autorreferenciabilidade seria visualizada tanto no Direito, como no ser humano e na empresa, cada um como sistema de reprodução autopoiético (LUHMANN, 1995, p. 55), respectivamente: o sistema social funcional com a comunicação jurídica (Direito); o sistema psíquico ligado às decisões (homem); e o sistema organizativo de complexidade interna (empresa) (GÓMEZ-JARA DIEZ, 2015, p.19-36).

De forma equivalente, o autor sustenta que a imputabilidade empresarial seria expressa pela formação de uma racionalidade complexa suficiente, capaz de se autodeterminar e se autoconduzir, assim como a psique humana. Tal complexidade seria constatada pela formação de sistemas internos de comunicação, órgãos e departamentos de fidelidade às normas (LINHARES; OLIVEIRA, 2015, p. 46).

Ainda sobre o tema, o jurista espanhol leciona:

Dito de outra maneira, ao longo do tempo se produz uma acumulação de círculos autorreferenciais no âmbito empresarial até chegar a um encadeamento hipercíclico dos mesmos, momento em que emerge verdadeiramente o autor corporativo (corporateactor) como sistema autopoiético de ordem superior. Estes círculos autorreferenciais se dão em quatro âmbitos diferentes: o limite do sistema, a estrutura do sistema, os elementos do sistema e a identidade do sistema. Assim, o limite do sistema organizativo é dado pela condição de membro (Mitgliedschaft); a estrutura se materializa nos programas de decisão - tanto finais como funcionais - que regem a organização; os elementos do sistema, isto é, as unidades basais ou operações que constituem a autopoiese do sistema organizativo são as decisões; e, finalmente, a identidade do sistema vem determinada pela denominada identidade corporativa.(GÓMEZ-JARA DIEZ, 2015, p. 34-35) 
Portanto, a empresa que possui esse nível de constituição e processamento, obtida com o seu desenvolvimento ao longo do tempo, e que realiza ilícito ambiental, poderá ser imputável. Com o uso de equivalentes funcionais (meio de semelhança) com a teoria para pessoa física, o autor continua formando a teoria do crime para pessoas jurídicas, explica-se.

Se para a teoria do delito clássica o injusto penal é a ação valorada antijuridicamente, ou seja, a sua contradição com uma norma jurídica (JESCHECK, 1993, p. 315), para as pessoas jurídicas o injusto seria definido como a organização defeituosa da corporação, e até inexistente (GÓMEZ-JARA DIEZ, 2015, p. 51).

A culpabilidade, por sua vez, para a dogmática penal tradicional, é conceituada pela reprovação pessoal do autor, em razão da prática de um ato contrário ao Direito, podendo agir de outro modo. É a reprovação da forma que direciona a sua vontade, sendo censurada a sua capacidade, liberdade e consciência (BUSATO, 2015, p. 538).

Destarte, seria dividida em três elementos, quais sejam: imputabilidade (capacidade de ser responsabilizado, desde que preenchidos fatores físicos, biológicos, psíquicos e psicossociais); potencial consciência de ilicitude (possibilidade de conhecimento de que a conduta não é permitida); (BUSATO, 2015, p. 556-573)e exigibilidade de conduta diversa (poder agir conforme o Direito)

Por outro lado, a culpabilidade do ente moral estaria ligada à cultura corporativa de infidelidade ao Direito, de não cumprimento do ordenamento jurídico (GÓMEZ-JARA DIEZ, 2015, p. 51). Assim, são abandonadas as condições antropocêntricas da dogmática penal vigente.

Nessa linha salienta Fábio André Guaragni:

\begin{abstract}
No que concerne à culpabilidade por déficit de organização, ente Gómez-Jara que o padrão de responsabilidade para as empresas consiste na censura pela falta de esforços organizativos que buscam o cumprimento do Direito: daí, haver um déficit na organização. Tendo em vista que o injusto praticado pela pessoa jurídica põe em risco interesses protegidos pelo Direito Penal, sobre a corporação deve recair um juízo de reprovação, já que poderia ter prevenido a ocorrência do injusto adotando um modelo de organização que a prevenção operasse.(GUARAGNI, 2014, p. 133)
\end{abstract}

Quanto às figuras do dolo e da imprudência, localizadas no tipo subjetivo, revelando, respectivamente, o conhecimento dos elementos do crime e a intenção de praticá-lo, ou de assumir o risco, para o primeiro, e a violação do dever de cautela, para o segundo (DOTTI, 2012, p. 403-404). Para o modelo construtivista, a definição de dolo seria “"[...] o conhecimento organizacional da realização de um determinado resultado lesivo, e da imprudência como o dever de possuir tal conhecimento." (GÓMEZ-JARA DIEZ, 2015, p. 98). 
De mais a mais, acerca das particularidades da pena, diferentemente da teoria mista adotada para agentes físicos, na qual se tem os fins de prevenção e repressão, o modelo da autorresponsabilidade, de outro lado, destacaria a retribuição comunicativa, que visa reestabelecer, mediante a comunicação, a vigência da norma, o reforço ao seu cumprimento (GÓMEZ-JARA DIEZ, 2015, p. 44). Essa ideia se assemelha ao Funcionalismo Sistêmico de Günter Jakobs ${ }^{4}$.

Como símbolo da concretização do modelo construtivista analisado, tem-se o compliance program, aparelhamento empresarial de integridade, que se revela, segundo o autor, como meio justo e eficaz de constatação da organização da corporação e sua cultura (GÓMEZJARA DIEZ,2015, p. 4).

Em outras palavras, o programa de cumprimento de normas e regulamentos seria útil na análise da responsabilidade penal do ente moral, de modo que diferenciaria quem é fiel ao Direito, daqueles que não são, especialmente na aferição da culpabilidade. Para além, pode figurar como hipótese exculpante, considerando a implantação de uma organização complexa correta e uma cultura de licitude (GÓMEZ-JARA DIEZ, 2015, p. 04).

Por derradeiro, relevante salientar que, apesar das críticas ao molde teórico de GómezJara Diez, no sentido do desconhecimento pelos operadores do Direito da complexidade empresarial para fazer um juízo valorativo sobre a sua organização e sobre a efetividade do programa de integridade, e mais, da possibilidade de o ente moral utilizar este aparelhamento para cometer injustos penas e permanecer impune (BUSATO, 2013, p. 178-180), não há como negar a existência de vantagens de ordem dogmática e político-criminal adquiridas com o construtivismo.

A presente base teórica traz contribuições não somente ao afastamento da dependência da dupla imputação, para que a pessoa jurídica possa ser devidamente punida, bem como a apresenta o sustentáculo dogmático desta responsabilização, a partir de uma reformulação da teoria clássica do delito, superando suas deficiências.

Nesse sentido, fundamenta, por meio dos sistemas de autorreferenciabilidade, a capacidade de ação, a ilicitude, a culpabilidade, a distinção entre dolo e culpa, todos utilizados para a configuração do ente jurídico criminoso. Também diferencia aquele que é imputável daquele que não é, desde que exista uma organização empresarial complexa.

\footnotetext{
${ }^{4}$ A Teoria Funcionalista Sistêmica, também conhecida como Teoria do Sistema Fechado ou da Autopoiese, visualizava a reprimenda como forma de restauração da validade da norma. Quer dizer, a pena era estabelecida para o fim de resgatar a funcionalidade e a ordem do sistema, minimizando a frustração instalada pelo delito perpetrado.
} 
Ademais, torna viável a previsão legal de hipóteses exculpantes, o que beneficia a imagem, a reputação e o funcionamento da corporação, evitando sanções ou reduzindo-as, se cabalmente demonstrada a adoção de um programa de integridade justo e efetivo, ou seja, que não seja de fechada. Melhor dizer, aquele que comprovar a cultura de cumprimento de normas.

Logra êxito, então, na adaptação do Direito Penal com a nova sociedade, delineada pelo risco de prejuízos, imensuráveis e abstratos, que podem atingir a interação ecológica, deixando marcas para as futuras gerações. Por isto, revela a importância da proteção do meio ambiente sustentável, além da necessidade da cooperação entre Estado e entidades particulares autorregulação através do compliance - para o seu resguardo, com a evitação de ilícitos penais nesse âmbito.

Convém, somente, exigir requisitos do compliance program tangentes a eficácia e efetivo funcionamento que impeçam a adoção apenas cosmética do programa, com a incidência indevida da exculpação.

\section{CONSIDERAÇÕES FINAIS}

Diante do exposto, verifica-se que a relação entre homem e natureza foi modificada ao longo dos anos, de uma relação pacífica e igualitária, à uma exploração ecossistêmica ilimitada e irracional. Isto porque, como resultado das Revoluções Francesa e Industrial, ocorreu a transformação socioeconômica e ambiental, a partir da supremacia da razão humana, da intensificação do desenvolvimento tecnológico aliada à produção industrial em larga escala e à escassez dos recursos naturais.

Então, devido a conscientização do esgotamento dos referidos recursos e dos novos riscos de danos contra toda a coletividade intergeracional - crise existencial -, a Constituição Federal de 1988 instituiu pela primeira vez o direito fundamental ao meio ambiente ecologicamente equilibrado, como também atribuiu a tríplice responsabilidade (criminal, administrativa e civil) para a pessoa física ou jurídica, que perpetrar ilícitos ambientais.

Em cumprimento à cláusula constitucional criminalizadora, a Lei de Crimes Ambientais legislou acerca dos tipos penais ambientais e da responsabilidade penal do agente criminoso (físico e jurídico). No que tange ao ente moral, foi interpretado inicialmente segundo um modelo de heterroresponsabilidade, na qual condiciona a punição da corporação ao processamento e à condenação da pessoa física, expressando, assim, a dupla imputação e a 
coautoria. Apesar de ser compatível com a teoria clássica do delito, apresenta problemas dogmáticos e de política-criminal e, consequentemente, contribui com a impunidade.

Assim, objetivando a superação de falhas da atuação do Direito Penal na punição de pessoas jurídicas, salientou-se o modelo de autorresponsabilidade, na qual a organização empresarial é responsabilizada por fato próprio, independente de responsabilização da pessoa física.

Nesta toada, tem-se a teoria da autorresponsabilidade com fundamento construtivista luhmanniano lecionada pelo jurista espanhol Gómez-Jara Diez, a qual configura o sustentáculo da teoria do crime e da pena para o ente coletivo. Logo, o agente, de estrutura e organização complexa (defeituosa ou insuficiente), capaz de criar os seus próprios elementos e de se autorregular, tendo como prevalente a cultura de infidelidade com o Direito, seria caracterizado como responsável criminal, podendo sofrer reprimenda, desvencilhada do autor físico.

Como visto, o aparato teórico estudado traz grande contribuição dogmática e de política-criminal, afinal, logra êxito em adaptar o Direito Penal às necessidades da atual Sociedade de Risco, como a existência de uma teoria autônoma do crime para corporações que cometem delitos ambientais e a diminuição da sua impunidade. Mais ainda, fomenta a aplicação de programas de compliance, os quais constituem não apenas meio probatório da imputação da pessoa jurídica, como também proporcionam conscientização maior do resguardo ambiental, afastando condutas antiecológicas do âmbito econômico.

\section{REFERÊNCIAS}

AYALA, Patrick Araujo. A proteção jurídica das futuras gerações na sociedade de risco global: o direito ao futuro na ordem constitucional brasileira. In: FERREIRA, Heline Sivini; LEITE, José Rubens Morato (orgs.). Estado de direito ambiental: tendências. Aspectos consticionais e diagnósticos. Rio de Janeiro: Forense Universitária, 2004.

BAHIA, Carolina Medeiros Bahia. Noção jurídica de risco ao meio ambiente e sua proteção no sistema brasileiro de responsabilidade civil ambiental.Revista de Direito Ambiental,São Paulo, v. 73, 2014. p. 123-140.

BECK, Ulrich. La sociedade Del riesgo global: amor, violencia y guerra. 2.ed. Madrid: Siglo, XXI, 2006.

BECK, Ulrich. World at risk. Cambridge: Polity Press, 2009.

BECK, Ulrich. Sociedade de Risco: Rumo a uma nova modernidade. 2.ed. São Paulo: Editora 34, 2011. 
BRASIL. Constituição da República Federativa do Brasil (1988). 13. ed. São Paulo: Saraiva, 2012.

BRASIL. Lei $n^{\circ} 9.605$ de 12 de fevereiro de 1998. Dispõe sobre as sanções penais e administrativas derivadas de condutas e atividades lesivas ao meio ambiente, e dá outras providências. 13. ed. São Paulo: Saraiva, 2012.

BRASIL. Supremo Tribunal Federal. RE 548181, Relatora Min. ROSA WEBER, Primeira Turma, julgado em 06/08/2013. Disponível em: http://redir.stf.jus.br/paginadorpub/paginador.jsp?docTP=TP\&docID=7087018. Acesso em: 18 nov. 2019.

BUSATO, Paulo César. Crítica ao modelo construtivista de culpabilidade da pessoa jurídica. Revista Justiça e Sistema Criminal. Curitiba, v. 5, n. 9, jul./dez., 2013. p. 167-182.

BUSATO, Paulo César. Direito Penal: parte geral. 2. ed. São Paulo: Atlas, 2015.

CIRNE, Mariana Barbosa. O que é direito constitucional ao meio ambiente ecologicamente equilibrado?.Revista de Direito Ambiental.São Paulo, v. 90, a. 23, abr./jun. São Paulo, 2018. p. 223-241.

DETZEL, Andre Eduardo. Alternativas para a superação da vedação dogmática da culpabilidade penal da pessoa jurídica nos modelos de heteroresponsabilidade e autorresponsabilidade. Dissertação apresentada ao Programa de Mestrado em Direito Empresarial e Cidadania do Centro Universitário Curitiba, como requisito parcial à obtenção do Título de Mestre em Direito. Curitiba, 2016. Disponível em: https://www.unicuritiba.edu.br/images/mestrado/dissertacoes/2016/Andre_Eduardo_Detzel.pd f. Acesso em: 18 nov. 2019.

DOTTI, René Ariel. A incapacidade criminal da pessoa jurídica (Uma perspectiva do direito brasileiro). In: PRADO, Luiz Regis. Responsabilidade penal da pessoa jurídica: fundamentos e implicações. São Paulo: Revista dos Tribunais, 2001. p. 141-180.

DOTTI, René Ariel. Curso de Direito Penal: parte Geral. 4. ed. ver., atual. e ampl. com a colaboração de Alexandre Knopfholz e Gustavo Britta Scandelari. São Paulo: Revista dos Tribunais, 2012.

ESTELLITA, Heloisa. Responsabilidade penal de dirigentes de empresas por omissão: estudo sobre a responsabilidade omissiva imprópria de dirigentes de sociedades anônimas, limitadas e encarregados de cumprimento por crimes praticados por membros da empresa. São Paulo: Marcial Pons, 2017.

FERREIRA, Heline Sivini. A biossegurança dos organismos transgênicos no direito 
ambiental brasileiro: Uma análise fundamentada na teoria da sociedade de risco. 2008. 372 f. Tese (Doutorado em Direito) - Universidade Federal de Santa Catarina, Florianópolis, 2008. Disponível em: https://repositorio.ufsc.br/handle/123456789/91741. Acesso em: 20nov. 2019. FERREIRA, Daniel. Alternativas legais à sanção administrativo-ambiental: uma eventual questão de dignidade da pessoa humana e de sustentabilidade da atividade empresarial. Revista Juridica, [S.1.], v. 22, n. 6, p. 55-75, jun. 2009. ISSN 2316-753X. Disponível em: <http://revista.unicuritiba.edu.br/index.php/RevJur/article/view/99/74>. Acesso em: 17 abr. 2020. doi:http://dx.doi.org/10.21902/revistajur.2316-753X.v22i6.99.

FIGUEIREDO, Guilherme Gouvêa de. Crimes Ambientais à Luz do Conceito de Bem Jurídico-Penal:(des)criminalização, redação típica e (in)ofensividade. São Paulo: IBCCRIM, 2008. 274p. ISBN 978-85-99216-10-1 (Monografias ; 47)

GOLDBLATT, David. Teoria social e ambiente. Traduzido por Ana Maria André. Lisboa: Instituto Piaget, 1996.

GOMES, Luiz Flávio; BIANCHINI, Alice. O Direito Penal na era da globalização. São Paulo: Revista dos Tribunais, 2002.

GOMES, Luiz Flávio; MACIEL, Silvio. Crimes ambientais: comentários à lei 9.605/98. São Paulo: Revista dos Tribunais, 2011.

GÓMEZ-JARA DÍEZ, Carlos. A Responsabilidade Penal da Pessoa Jurídica: Teoria do crime para pessoas jurídicas. São Paulo: Atlas, 2015.

GUARAGNI, Fábio André. Responsabilidade Penal do ente coletivo: Pilastras PolíticoCriminais derivadas das noções de Sociedade de Risco e Alteridade. In:Aspectos contemporâneos da responsabilidade penal da pessoa jurídica. v. 2. São Paulo: Federação do Comércio de Bens, Serviços e Turismo do Estado de São Paulo, 2014.

HOBSBAWN, Eric. A era das revoluções: 1789 - 1848. 25 ed. São Paulo: Editora Paz e Terra, 2010.

HOFMEISTER, Maria Alice Costa. O Dano Pessoal na Sociedade de Risco. Rio de Janeiro: Renovar, 2002.

IANNI, Octavio. A sociologia e o mundo moderno. Rio de Janeiro: Civilização Brasileira, 2011.

JESCHECK, Hans Heinrich. Tratado de Derecho Penal. Trad. José Luis Manzanares Samaniego. 4. ed. Granada: Comares, 1993.

LEFF, Enrique. Epistemologia ambiental. Trad.de Sandra Velenzuela. 5. ed. São Paulo: Cortez, 2010. 
LEITE, José Rubens Morato; BELCHIOR, Germana Parente Neiva. Dano ambiental na sociedade de risco: uma visão introdutória. In: LEITE, José Rubens Morado (coord.); FERREIRA, Heline Sivini; FERREIRA, Maria Leonor Paes C. (orgs.). Dano ambiental na sociedade de risco. São Paulo: Saraiva, 2012.

LINHARES, Sólon Cícero; OLIVEIRA, Daniele Aparecida de. O conceito construtivista de culpabilidade e a responsabilidade penal das pessoas jurídicas por crimes ambientais. Uma análise através da figura do compliance programs. Revista Jurídica (Furb). Blumenau, v. 19, n. 40, set./dez., 2015. p. 41-60.

LUHMANN, Niklas. Soziologische Aufklärung: Bd. VI: Die Soziologieund der Mensch, 1995.

LUISI, Luiz. Notas sobre a responsabilidade penal das pessoas jurídicas. In: PRADO, Luiz Regis. Responsabilidade penal da pessoa jurídica: fundamentos e implicações.São Paulo: Revista dos Tribunais, 2001. p. 141-180.

PISA, Adriana. Direito penal ambiental x sociedade de risco de Ulrich Beck: uma abordagem crítica. Revista de Direito Ambiental. São Paulo, abr./jun., v. 14, n. 54, 2009. p. 09-64.

PRADO, Luiz Regis. Responsabilidade penal da pessoa jurídica: em defesa do princípio da imputação penal subjetiva. In:PRADO, Luiz Regis. Responsabilidade penal da pessoa jurídica: fundamentos e implicações.São Paulo: Revista dos Tribunais, 2001. p. 101-135.

RUTTE, Israel; KOZICKI, Katya; RIOS, Rodrigo Sánchez. Sociedade de risco, recrudescimento da criminalidade e o crime de perigo abstrato. 2013. 149 p. Dissertação (Mestrado) - Pontifícia Universidade Católica do Paraná, Curitiba, 2013. Disponível em: http://www.biblioteca.pucpr.br/tede/tde_busca/arquivo.php?codArquivo=2855. Acesso em: 20 nov. 2019.

SÁNCHEZ, Jesús-Maria Silva. La expansión Del Derecho Penal: aspectos de La política criminal em lãs sociedades postindustriales. 2. ed. Madri: Civitas, 2001.

SCHECAIRA, Sérgio Salomão. Responsabilidade penal da pessoa jurídica. 2. ed. São Paulo: Método, 2003.

TIEDEMANN, Klaus. La responsabilitapenale de le persone giuridiche nel ciritto comparatto. Rivista Italiana di Diritto e Procedura Penale, Milano, v. 38, 1995. p. 615-533. 